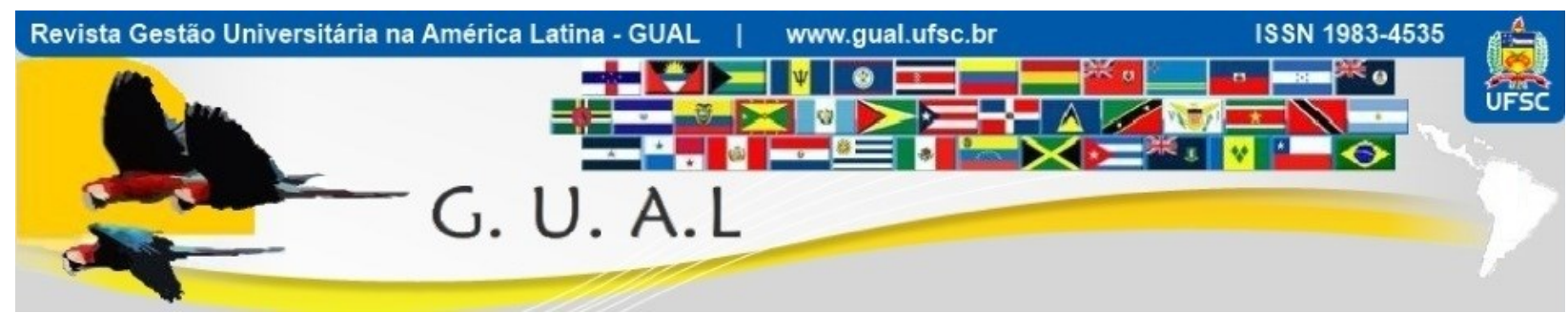

DOI: http://dx.doi.org/10.5007/1983-4535.2016v9n1p234

\title{
O IMPACTO DA QUALIDADE DE ENSINO NA CONSTRUÇÃO DO RELACIONAMENTO ENTRE ALUNO E MARCA DA UNIVERSIDADE
}

\author{
THE QUALITY OF EDUCATION IMPACT ON THE CONSTRUCTION OF \\ RELATIONSHIP BETWEEN STUDENT AND THE UNIVERSITY'S BRAND
}

Elder Semprebon, Doutor

Universidade Federal do Paraná - UFPR

elder.semprebon@gmail.com

Marcela Patricia Schikovski, Graduada Pontifícia Universidade Católica do Paraná - PUCPR ma.schikovski@gmail.com

Natalia Takasaki Motta, Graduada Pontifícia Universidade Católica do Paraná - PUCPR nahtakasaki@gmail.com

Martin de La Martinière Petroll, Doutor Universidade Federal de Santa Catarina - UFSC martin_petroll@yahoo.com.br

Rudimar Antunes da Rocha, Doutor Universidade Federal de Santa Catarina - UFSC rrudimar@hotmail.com

Recebido em 24/agosto/2014

Aprovado em 11/novembro/2015

Sistema de Avaliação: Double Blind Review

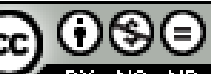

Esta obra está sob uma Licença Creative Commons Atribuição-Uso. 


\title{
RESUMO
}

O objetivo deste estudo é avaliar a influência da qualidade de ensino no relacionamento dos alunos com a marca da IES. Assim, tem-se como hipótese de pesquisa que o relacionamento aluno/aluno e professor/aluno, a estrutura oferecida pela IES, a qualificação do docente e os métodos de ensino, sendo fatores da qualidade de ensino, influenciam positivamente o relacionamento do aluno com a marca da IES. Para atendimento do objetivo propõe-se uma nova escala para mensurar a qualidade de ensino e utiliza-se uma escala de qualidade do relacionamento já validada no contexto brasileiro. O estudo desenvolveu-se em três etapas: (1) pesquisa bibliográfica e entrevista em profundidade para geração dos itens da escala de qualidade de ensino, (2) levantamento para purificação dos itens da escala de qualidade de ensino e (3) novo levantamento para validação da escala de qualidade de ensino e teste da hipótese através de modelagem de equações estruturais. Os resultados apontam que a influência da qualidade de ensino no relacionamento dos alunos com a marca da IES alcança $75,9 \%$. Comprovou-se ainda que alunos não bolsistas, homens e aqueles que estão no início do curso são mais sensíveis à relação.

Palavras-chave: Gestão Universitária. Qualidade de ensino. Relacionamento com a marca.

\begin{abstract}
The objective of this study is to evaluate the influence of the quality of education on the relationship between students and the university's brand. Therefore, the research hypothesis is that the relationship student-student and professor-student, the structure offered by the universities, the professor's qualification and the teaching methods, all factors of the quality of education, positively influence the student's relationship with the brand of the university. With this in mind, it is proposed a new scale to measure the quality of education and it is used a scale of the quality of relationship previously validated in the Brazilian context. The study was done in three steps: (1) bibliographic research and in-depth interview to generate the items for the quality of education scale, (2) survey to purify the items of the quality of education scale and (3) new survey to validate the quality of education scale and hypothesis test through Structural Equation Modeling. Results show that the influence of the quality of education in student's relationship with the university's brand overtake $75.9 \%$. It was also found that students with no fellowship, men and those who are at the beginning of the course are more sensitive to that relationship.
\end{abstract}

Key-words: University management. Quality of education. Relationship with the brand. 


\section{INTRODUÇÃO}

Com a promulgação da Lei de Diretrizes e Bases (1996) no contexto educacional, surge um ambiente favorável para o crescimento do número de instituições de ensino superior (IES) no Brasil (MAINARDES; DOMINGUES, 2010). Diante deste cenário de competitividade, as estratégias de marketing de relacionamento tornam-se importantes para que as IES possam reter seus alunos. Conforme Walter, Tontini e Domingues (2005), a educação torna-se parte de um mercado onde a qualidade dos serviços e a satisfação dos clientes são fundamentais para a sobrevivência das instituições. Scaglione e Piza (2011) afirmam que as IES também precisam atentar-se, como qualquer outro setor que enfrente aumento da concorrência, com a retenção de seus alunos.

Para Santini, Guimarães e Severo (2014), entender a intensidade do relacionamento, a partir de estudos empíricos, pode contribuir para a assertividade das decisões gerenciais no que tange ao investimento em ações de manutenção de clientes e captação de novos clientes, bem como estes estudos ampliam a visão acadêmica sobre o tema do marketing de relacionamento.

Neste contexto, é necessário compreender os fatores que contribuem para o aumento da intensidade do relacionamento dos alunos com a instituição. Assim, este estudo lança proposições sobre dois construtos ainda não relacionados na literatura de marketing e de gestão universitária: qualidade de ensino e relacionamento dos alunos com a marca da IES. Para tanto, objetiva-se desenvolver uma escala para mensuração da qualidade de ensino e também avaliar a influência deste construto no relacionamento dos alunos com a marca da IES.

A qualidade de ensino é representada neste estudo por quatro fatores: o método de ensino, a qualificação do corpo docente, a estrutura da IES e o relacionamento entre alunos e professores. Para a mensuração deste construto o estudo propõe uma nova escala.

Já o relacionamento dos alunos com a marca da IES foi medido utilizando a escala de qualidade do relacionamento com marcas proposta por Francisco-Maffezzolli, et al. (2013). Esta escala é composta por seis fatores que explicam as ligações afetivas, comportamentais e cognitivas com a marca. O pressuposto para uso deste construto é a capacidade humana de se relacionar com objetos antropomorfizados (marca), questão bastante evidenciada na literatura de relacionamento com marcas. 
O estudo apoia-se em testes estatísticos para validar a nova escala proposta e testar a relação hipotetizada. Para complementar os achados, realizou-se análises de moderação que revelam um público mais sensível com a importância dada à qualidade de ensino na construção do relacionamento com a marca da IES.

\section{REVISÃO TEÓRICA}

Neste capítulo serão abordados os conceitos teóricos que embasaram a construção desta pesquisa, sendo marketing de relacionamento, qualidade do ensino e o relacionamento entre consumidor e marca.

\subsection{GESTÃO UNIVERSITÁRIA E MARKETING DE RELACIONAMENTO}

Kotler e Fox (1994) afirmam que as instituições passaram a se conscientizar da importância do marketing, quando seus mercados passaram a sofrer mudanças, devido a novos concorrentes ou a novas necessidades dos consumidores. Scaglione e Piza (2011) afirmam que as IES precisam preocupar-se também, como qualquer outro setor que enfrente aumento da concorrência, com a retenção de seus alunos.

O conceito de relacionamento tornou-se um importante tópico nos negócios, em parte devido às vantagens econômicas que as empresas estão assumindo para aproveitar os resultados positivos do relacionamento consumidor/marca. Estas vantagens incluem os custos menores em programas de marketing, facilidade de acesso aos clientes, aquisição e retenção de consumidores, criação de brand equity e incremento nos lucros. Relacionamentos são pensados para melhorar a posição das empresas por meio do incremento dos fluxos de caixa, baixa da volatilidade, estabelecimento de barreira a entrantes e oferecer a possibilidade do aumento de preços e fatia do mercado (ASHWORTH; DACIN; THOMSON, 2009).

Neste contexto pode-se afirmar que as IES devem buscar concretizar estratégias de marketing de relacionamento, o qual pode ser definido, segundo Prado (2004), como um esforço integrado da empresa para desenvolver (atrair, manter e reforçar) relacionamentos com consumidores imediatos e/ou finais, de forma a desenvolver benefícios mútuos a partir desta relação e a criar valor entre as partes. Já para Gummesson (2010), o marketing de relacionamento é geralmente descrito como uma abordagem para desenvolver clientes leais de longo prazo e, dessa forma, aumentar a lucratividade. Para manter a continuidade de um 
relacionamento, as empresas buscam garantir a qualidade dos serviços prestados e a própria qualidade do relacionamento com os consumidores (HENNIG-THURAU; HANSEN, 2001).

Inúmeros são os benefícios trazidos para a IES por meio do estabelecimento de relações duradouras com os alunos. O relacionamento de longo prazo entre aluno e instituição é uma vantagem competitiva. (ALVES, 2003). A pesquisa de Costa, Costa e Bergamo (2014) identificou que o investimento em uma filosofia de marketing de relacionamento é importante para o estabelecimento de uma relação atitudinal entre instituições educacionais e seus clientes. O atributo satisfação se mostrou como um grande diferencial na escolha da IES e um dos elementos necessários para a retenção e lealdade na educação do ensino superior na instituição escolhida. Santini, Guimarães e Severo (2014) demonstraram quantitativamente que a qualidade percebida, o comprometimento e a confiança, sendo construtos que formam o relacionamento, apresentam uma relação positiva com a retenção de alunos. O estudo de Mainardes e Domingues (2010) demonstrou estatisticamente que para os universitários desenvolverem lealdade à sua IES, a imagem e a credibilidade da marca da instituição são essenciais.

\subsection{RELACIONAMENTO ENTRE CONSUMIDORES E MARCAS}

Uma corrente teórica importante na explicação do fenômeno do relacionamento entre consumidores e marcas é a adoção dos conceitos de relacionamentos interpessoais, apoiandose na teoria da personalidade da marca (Aaker, 1997) e nas evidências apresentadas por Belk (1988), o qual estabelece que um consumidor é capaz de relacionar-se com objetos inanimados, atribuindo a eles traços de personalidade. Para que a marca seja acessível cognitivamente e parceira ao homem, este procura humanizá-la, personalizá-la e torná-la animada. Isto se dá pelo princípio da antropomorfização (Thomson; Macinnis; Park, 2005).

Nesta linha, destaca-se a pesquisa seminal de Fournier (1998), que propõe o componente de avaliação do relacionamento denominado "Qualidade do Relacionamento com a Marca", defendendo a ideia de que as marcas podem e servem como parceiras de relacionamento, e relacionamentos consumidor/marca são válidos ao nível de experiências vivenciadas. As marcas servem como repositores poderosos de significados e são empregadas na substanciação, criação e reprodução de conceitos pessoais. Há evidências do papel ativo dos consumidores na construção da cultura atual através da relação com marcas (FOURNIER, 1998). De acordo com Fournier (1998), a qualidade do relacionamento com uma marca 
resulta de três tipos de ligações: (1) ligações afetivas e sócio emotivas (amor/paixão e autoconexão); (2) ligações comportamentais (interdependência e comprometimento); e (3) ligações cognitivas (intimidade e parceria).

\section{Construto}

Amor/Paixão

Autoconexão

Interdependência

Intimidade

Parceria/Confiança

Quadro 1 Construtos da Qualidade do Relacionamento com Marcas.

Fonte: Adaptado de Fournier (1998); Prado (2004; et al 2009). (FOURNIER, 1998). 1998; PRADO, 2004). e preeminência (FOURNIER, 1998).

A pesquisa de Francisco-Maffezzolli, et al. (2013) apresenta indicadores para

Retrata aspectos de afeto positivo forte em direção à marca, inclusive convicções na singularidade da relação e não possibilidade de substituição do parceiro de relacionamento. Além das teorias emprestadas de relacionamentos íntimos, esta dimensão refere-se explicitamente às respostas afetivas de longo-prazo associadas à marcas

Refere-se ao grau com que o relacionamento com a marca dá suporte à metas, tarefas, e temas da vida do consumidor, ou ajuda a expressar seus conceitos reais, desejados, ou coletivos, indicando uma ativação de um sistema de conexão pessoal (FOURNIER, 1998).

Retrata a participação da marca na vida cotidiana do consumidor, tanto psicologicamente (por exemplo, como com dependências e obsessões) e comportamentalmente (por exemplo, hábitos, rotinas e rituais) (FOURNIER, 1998). Esta dimensão incorpora ainda a perspectiva dos estilos de conexão, que, além de tratar da natureza do relacionamento, rememora aspectos que estão associados à história que o consumidor pode ter com seus diversos relacionamentos com marcas (FOURNIER, 1998; PRADO, et al. 2009).

A intenção continuar a relação no futuro, apesar de circunstâncias imprevistas. Inclua uma vontade para anteceder alternativas atraentes, e fazer sacrifícios e investimentos na relação com o passar do tempo. Esta dimensão é amplamente descrita na literatura de relacionamento $\mathrm{B} 2 \mathrm{~B}$, e recentemente incorporada também no contexto B2C (FOURNIER,

Refere-se a uma sensação de compreensão recíproca entre companheiros de relacionamento. Inclui o conhecimento e a familiaridade dos consumidores com a marca, e percepções de familiaridade da marca com o consumidor (FOURNIER, 1998).

Corresponde à avaliação global do consumidor da eficácia da marca em seu papel no relacionamento. Incluem percepções da probidade do companheiro de marca, sua receptividade para necessidades pessoais, e o sentimento do consumidor de estar sendo bem cuidado na relação desenvolvida, em que suas necessidades pessoais recebem atenção mensuração dos construtos da qualidade do relacionamento, os quais foram utilizados nestas pesquisas.

\subsection{QUALIDADE DE ENSINO}

No universo acadêmico não se pode ignorar a importância da interação entre professores e alunos e as relações decorrentes desse convívio. Indivíduos precisam manter um convívio com outros para construir sua personalidade e para interagir com o mundo ao seu redor. Em um estudo realizado por Ikeda e Bacellar (2008), sobre a relação estabelecida entre professores e alunos durante a vida acadêmica, muitos docentes declararam em entrevistas que um fator determinante da qualidade de seu trabalho é o fato de os alunos ainda se 
lembrarem, anos mais tarde, de suas aulas e ensinamentos, alguns até sendo influenciados na escolha de suas carreiras. Diante dessa afirmação é possível constatar que o grau da relação entre professor e aluno pode ser um fator determinante para a conexão estabelecida pelo aluno com a IES. O que dirige o processo educativo do aluno dentro da IES é a interação com o professor. A maneira pela qual essa interação ocorre é o que facilitará ou levará o aprendizado do aluno para uma ou outra direção (SANTOS, 2001). Esse processo educativo deve ter como foco a aprendizagem do aluno e não somente o ensino do professor (SANTOS, 2001). Rogers (1972) compreende essa relação estabelecida entre professor e aluno como a proposta de uma troca que facilita a aprendizagem, por meio da existência de algumas qualidades oriundas do comportamento do professor, como autenticidade, apreço ao aluno e empatia.

Os estudantes que frequentam uma instituição de ensino superior onde se sintam bem tendem a se desenvolver mais, sendo esta uma situação que deve ser tratada de forma a se tornar cultura organizacional dentro da instituição de ensino superior (McLaughlin; Brozovsky; McLaughlin 1998, apud Bergamo; GIULIANI, 2009). Para que as atividades acadêmicas sejam realizadas com eficácia e eficiência é necessário um sólido suporte de toda a estrutura administrativa e dos demais serviços necessários para viabilizar a vida acadêmica (TANI, 2007).

Em um levantamento realizado por Almeida (1997) foi possível compreender que muitas vezes na busca pela conquista de alunos, alguns atributos físicos como academia, fácil acesso a meios de transporte, um bom laboratório de informática, convênios com "grandes" empresas, uma praça de alimentação, ganham muito mais força do que o próprio curso ofertado pela IES.

Nesse sentido, as universidades mercantis acabam enfatizando outros aspectos que Levitt chama de produtos esperados pelo cliente (engana-se quem acredita que todo cliente procura somente ensino de qualidade), produtos aumentados (estratégias que ampliam o produto além do que é solicitado ou esperado pelo cliente), produtos potenciais (o que se pode acrescentar de novo ao produto) (CALDERÓN, 2000).

No processo de ensino-aprendizagem o apoio dado pelo professor ao aluno é um aspecto crucial (IKEDA; BACELLAR, 2008). A qualificação do corpo docente no que diz respeito à composição, formação e produção intelectual influencia fortemente na qualidade de ensino de graduação em qualquer área de conhecimento (TANI, 2007). 
Sem a oferta de professores qualificados e preparados adequadamente para atender à demanda dos cursos, a qualidade tende a declinar. O docente possui um compromisso com os temas educacionais, de maneira muito mais ampla do que apenas a transmissão de conhecimentos aos seus alunos e essa é uma questão que deveria estar constantemente em processo de reflexão (NOSSA,1999).

Ainda conforme Nossa (1999), educar é e deve ser um ato consciente e também intencional com o intuito de ultrapassar a simples etapa do instruir. Desse modo, um docente do ensino superior deve possuir domínio específico da sua área e habilidade de educar (NOSSA, 1999). A qualificação do docente deve ser adequada e entendida como uma condição de acesso à carreira e progressão dentro dela, se não for conduzida para a produção de bons resultados essa passa a ser irrelevante (CALDERÓN, 2000).

Por tudo isso, desenvolveu-se a seguinte hipótese:

H1 - O relacionamento aluno/aluno e professor/aluno, estrutura oferecida pela IES, a qualificação do docente e o método de ensino, como fatores da qualidade de ensino, influenciam positivamente a qualidade do relacionamento do aluno com a marca da IES.

\section{METODOLOGIA}

A partir da revisão literária e do objetivo do estudo apresenta-se o modelo de pesquisa baseado na hipótese a ser testada.

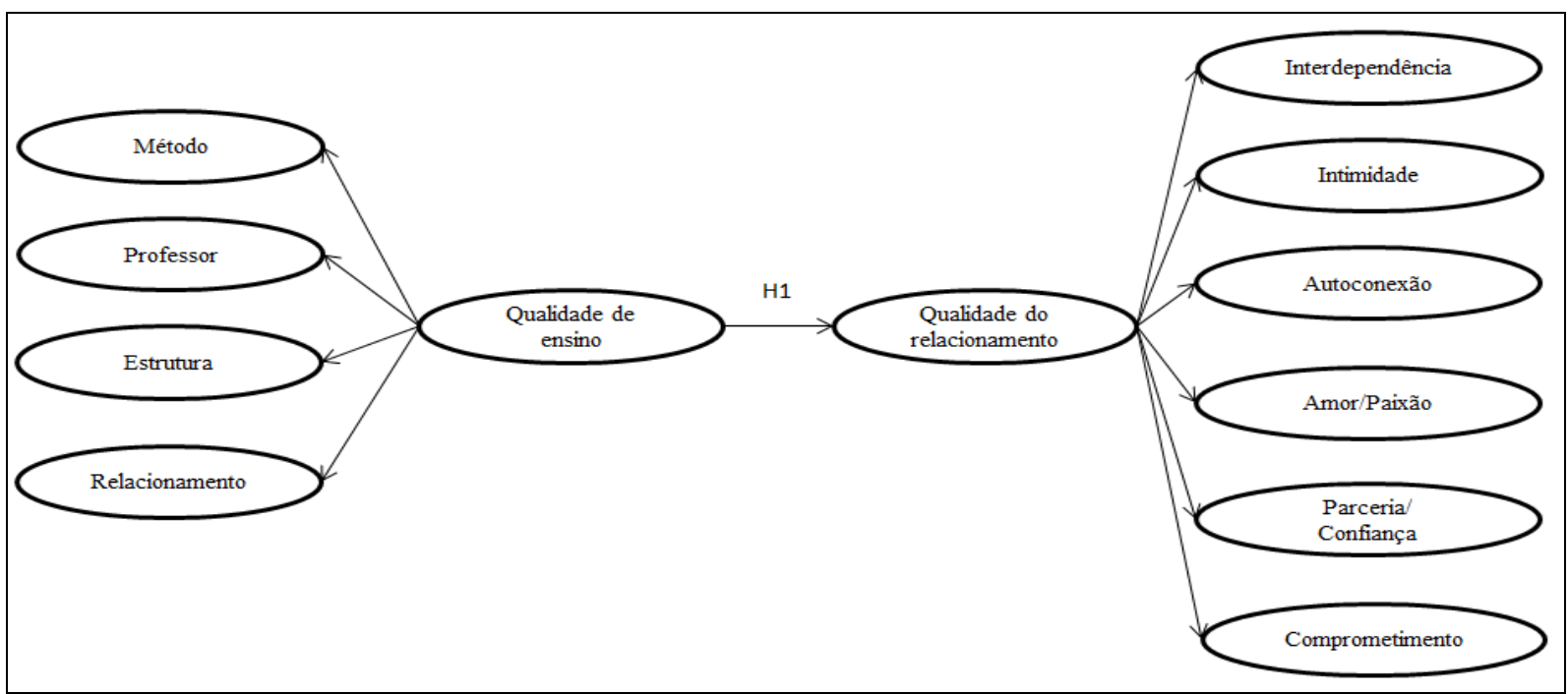

Figura 1 Modelo da pesquisa. Fonte: Os autores (2015). 
De acordo com os objetivos expostos inicialmente, que são desenvolver uma escala para mensuração da qualidade de ensino e avaliar a influência deste construto no relacionamento dos alunos com a marca da IES, a metodologia está dividida em duas partes.

$\mathrm{Na}$ primeira, adaptou-se os procedimentos para o desenvolvimento da escala de mensuração e de acordo com as propostas de Churchill (1979), Rossiter (2002) e Heere e James (2007) para o construto qualidade de ensino. Assim, primeiramente realizou-se a geração dos itens da escala por meio de pesquisa bibliográfica e entrevista em profundidade com seis alunos dos cursos de administração, marketing, contábeis e turismo de uma universidade privada do Sul do Brasil. Na sequência, buscou-se a purificação da escala realizando-se duas coletas quantitativas $(n=110$ e $n=291)$ via internet e presencialmente, obtendo-se respostas de alunos de diversos cursos e universidades. Através de duas análises fatoriais foi possível dimensionalisar os 24 itens gerados em quatro dimensões confiáveis. Posteriormente, pela análise fatorial confirmatória, validou-se a escala e suas dimensões.

A etapa seguinte foi dedicada ao segundo objetivo proposto pela presente pesquisa, que é o de avaliar a influência do construto da qualidade de ensino no relacionamento dos alunos com a marca da IES. Para isso, empregou-se a escala de Francisco-Maffezzolli, et al. (2013) para mensuração da qualidade do relacionamento com a marca. Nesta etapa, testou-se a hipótese do estudo por meio do uso de equações estruturais. Como análise complementar, verificou-se possíveis moderadores da relação.

\section{RESULTADOS}

Neste capítulo apresenta-se os resultados da pesquisa divididos em quatro seções, de acordo com o os objetivos e a proposta metodológica do estudo.

\subsection{GERAÇÃO DOS ITENS DA ESCALA DE QUALIDADE DE ENSINO}

A geração inicial dos itens da escala de qualidade de ensino foi realizada por meio de pesquisa bibliográfica e entrevista em profundidade com 6 alunos. A seguir encontra-se a análise da pesquisa qualitativa.

Muitos elementos do cotidiano dos alunos dentro da IES podem transmitir a percepção que estes têm do relacionamento estabelecido entre ele e a IES, atributos tangíveis como a relação entre professor-aluno, as instalações oferecidas pela instituição, a qualidade do corpo docente entre outros podem traduzir aos estudantes universitários sentimentos que mantêm 
essa relação ativa. Indivíduos precisam manter um convívio com outros indivíduos para construir sua personalidade e para interagir com o mundo ao seu redor. No universo acadêmico não se pode ignorar a importância da interação entre professores e alunos e as relações decorrentes desse convívio. O relacionamento entre professor e aluno não se dá somente pelo convívio em sala de aula, isso é percebido pelo estudante, conforme o entrevistado I relata abaixo:

"Porque eles passam e-mail particular pra gente, eles sempre se propõem a ajudar quando a gente tem algum problema pessoal, ou coisa assim. Eles nunca se negam apesar de não ser aquilo que é a função deles (ENTREVISTADO I)”.

O que dirige o processo educativo do aluno dentro da IES é a interação entre o professor e o aluno, a maneira pela qual essa interação ocorre é o que facilitará ou levará o aprendizado do aluno para uma ou outra direção (SANTOS, 2001). A percepção que os alunos possuem sobre esse relacionamento é visto de forma positiva, de acordo com o entrevistado II:

\footnotetext{
"Ótimo! Influencia nas notas né?! Tem um puxa-saquismo. E ajuda bastante, tendo mais acesso com eles você consegue ter mais atenção, e a sua dúvida sanada de melhor forma (ENTREVISTADO II)".
}

Rogers (1972) compreende essa relação estabelecida entre professor e aluno como a proposta de uma troca que facilita a aprendizagem, por meio da existência de algumas qualidades oriundas do comportamento do professor, como autenticidade, apreço ao aluno e empatia. Assim como uma boa relação estabelecida entre aluno e professor, uma dinâmica de aula diferenciada, intermediada por meio de tecnologias educacionais, jogos educativos, e até mesmo experiências vividas pelo docente impactam de forma positiva na relação desenvolvida entre eles.

Para que as atividades acadêmicas sejam realizadas com eficácia e eficiência, é necessário um sólido suporte de toda a estrutura administrativa e dos demais serviços necessários para viabilizar a vida acadêmica (TANI, 2007). Instituições que oferecem ferramentas diferenciadas em sala de aula ou até mesmo quando o professor possui uma iniciativa de tornar as aulas mais dinâmicas, de maior valor, também podem ser diferenciais importantes no relacionamento criado entre o aluno e a IES:

\footnotetext{
"Tem vários métodos hoje em dia, é, digamos a gente teve aula de mercado financeiro, ficamos mais na parte teórica a gente poderia digamos ter feito uma simulação, é, tem vários softwares hoje em dia que a gente pode e competir entre os alunos da sala de aula não ficar só na teoria, cada um vai lá, monta sua carteira de
} 
ações e competir entre nós mesmos e o vencedor ganhar mais... não ganha mais nota, mas ganha aprendizado (ENTREVISTADO I)".

Como relatado pelo entrevistado I, as novidades trazidas para sala de aula se não forem conduzidas de maneira correta pelo docente não agregam valor à formação do estudante. É uma soma de fatores que fazem com que cada vez mais as organizações educacionais exijam muito dos docentes em sua preparação (KARAWEJCZYK \& ESTIVALETE, 2002).

A qualificação do corpo docente no que diz respeito à composição, formação e produção intelectual influencia fortemente na qualidade de ensino de graduação em qualquer área de conhecimento (TANI, 2007).

Sem a oferta de professores qualificados e preparados adequadamente para atender à demanda dos cursos, a qualidade desses tende a declinar. $\mathrm{O}$ docente possui um compromisso com os temas educacionais, de maneira muito mais ampla do que apenas a transmissão de conhecimentos aos seus alunos e essa é uma questão que deveria estar constantemente em processo de reflexão (NOSSA,1999).

Tal percepção é clara para alguns alunos que destacam preferências entre alguns professores, que podem mudar a percepção que têm da IES, simplesmente por alguns professores não demonstrarem a importância de suas disciplinas e como poderão aplicá-las em seu cotidiano:

\footnotetext{
"Sim, tem alguns professores que eu não gosto porque ele falando eu não entendo nada e tem matérias que o conteúdo eu até acho interessante, mas que o professor dificulta muito (ENTREVISTADO IV)".
}

A transmissão dos conhecimentos quanto à qualidade do curso influencia na construção da imagem da IES. A qualificação, a capacidade didática em sala de aula e a motivação do docente, bem como o conteúdo do curso, constroem a percepção do aluno perante a qualidade de seu aprendizado (VIEIRA, TROCCOLI, DA SILVA, 2011).

Como resultado desta etapa foi possível gerar 24 itens para a proposição de uma escala de qualidade de ensino. Os itens foram testados quantitativamente e explicados nas seções subsequentes.

\subsection{PURIFICAÇÃO DOS ITENS DA ESCALA DE QUALIDADE DE ENSINO}

Após a geração dos itens pela pesquisa bibliográfica e qualitativa, segue-se a pesquisa com a purificação dos itens da escala. A primeira coleta de dados quantitativa foi realizada 
com aplicação presencial e virtual totalizando 110 casos válidos. A amostra possui predominância de indivíduos do sexo feminino (56,4\%), com média de idade de 21 anos, sendo $92,7 \%$ solteiros e $7,3 \%$ casados/vive junto, a maioria estudantes do quarto semestre (38,2\%). A amostra apresenta como principal forma de ocupação econômica $60,9 \%$ dos respondentes como estudantes, com renda familiar de aproximadamente R $\$ 5.241,00$ (29,1\%).

$\mathrm{Na}$ segunda coleta de dados, os questionários foram aplicados presencialmente em uma universidade no sul do país, totalizando 291 casos válidos. A amostra é predominantemente do sexo feminino $(56,1 \%)$, com média de idade de 22 anos, solteiros $(78,2 \%)$, cursando o primeiro semestre $(35,4 \%)$, funcionários de empresas privadas $(52,3 \%)$ e com renda familiar de aproximadamente $\mathrm{R} \$ 5.241,00(27,7 \%)$.

A partir destas coletas realizou-se a purificação da escala utilizando-se a Análise Fatorial Exploratória, pelo método de componentes principais e rotação Varimax. A tabela 1 apresenta os carregamentos dos itens nas dimensões que emergiram nas duas coletas, bem como outras medidas de esfericidade e confiabilidade.

Tabela 1 Análise Fatorial Exploratória (Coletas 1 e 2).

\begin{tabular}{|c|c|c|c|c|c|c|c|c|c|}
\hline & \multicolumn{5}{|c|}{ Coleta 1} & \multicolumn{4}{|c|}{ Coleta 2} \\
\hline & 1 & 2 & 3 & 4 & 5 & Método & Professor & Estrutura & $\begin{array}{c}\text { Relaciona } \\
\text { mento }\end{array}$ \\
\hline $\begin{array}{l}\text { O diálogo que tenho com } \\
\text { meus professores facilita o } \\
\text { meu processo de } \\
\text { aprendizagem. }\end{array}$ & & & & & $\begin{array}{l}0,49 \\
8\end{array}$ & & & & 0,513 \\
\hline $\begin{array}{l}\text { A maioria dos meus } \\
\text { professores procura criar } \\
\text { uma atmosfera agradável na } \\
\text { sala de aula. }\end{array}$ & & & $\begin{array}{l}0,72 \\
2\end{array}$ & & & & 0,496 & & \\
\hline $\begin{array}{l}\text { Quando há respeito mútuo } \\
\text { entre professor e aluno no } \\
\text { ambiente de sala de aula eu } \\
\text { tenho a oportunidade de ter } \\
\text { maior aprendizado. }\end{array}$ & & & & & $\begin{array}{l}0,77 \\
7\end{array}$ & & & & 0,67 \\
\hline $\begin{array}{l}\text { Os meus professores estão } \\
\text { acessíveis para responder às } \\
\text { minhas solicitações fora dos } \\
\text { horários de aula. }\end{array}$ & & & $\begin{array}{l}0,76 \\
8\end{array}$ & & & & & & 0,42 \\
\hline $\begin{array}{l}\text { Quando tenho fácil acesso } \\
\text { ao meu professor fora de } \\
\text { sala de aula me sinto mais } \\
\text { próximo dele. }\end{array}$ & & & & & $\begin{array}{l}0,51 \\
7\end{array}$ & & & & 0,782 \\
\hline $\begin{array}{l}\text { Percebo que meus } \\
\text { professores organizam suas } \\
\text { aulas de tal forma que } \\
\text { encorajam a interação entre } \\
\text { os alunos em sala de aula. }\end{array}$ & & & 0,72 & & & & & & 0,481 \\
\hline
\end{tabular}




\begin{tabular}{|c|c|c|c|c|c|c|}
\hline $\begin{array}{l}\text { Os meus professores } \\
\text { cumprem os prazos nas } \\
\text { atividades estabelecidas. }\end{array}$ & & & $\begin{array}{l}0,54 \\
2\end{array}$ & & 0,679 & \\
\hline $\begin{array}{l}\text { Os meus professores } \\
\text { dominam o conteúdo da } \\
\text { disciplina que lecionam. }\end{array}$ & & & $\begin{array}{l}0,71 \\
7\end{array}$ & & 0,723 & \\
\hline $\begin{array}{l}\text { Os meus professores } \\
\text { possuem criatividade para } \\
\text { usar a tecnologia de ensino } \\
\text { que está à disposição nas } \\
\text { salas de aula. }\end{array}$ & & & $\begin{array}{l}0,48 \\
2\end{array}$ & & 0,608 & \\
\hline $\begin{array}{l}\text { Os meus professores } \\
\text { transmitem suas ideias com } \\
\text { clareza e de forma efetiva. }\end{array}$ & & & $\begin{array}{l}0,75 \\
3\end{array}$ & & 0,685 & \\
\hline \begin{tabular}{lll} 
Os meus & \multicolumn{2}{c}{ professores } \\
apresentam a teoria e \\
aplicação prática dos \\
assuntos abordados em sala.
\end{tabular} & & & 0,54 & & 0,634 & \\
\hline $\begin{array}{l}\text { Os laboratórios ofertados } \\
\text { pela IES são adequadamente } \\
\text { equipados. }\end{array}$ & & $\begin{array}{l}0,71 \\
1\end{array}$ & & & & 0,79 \\
\hline $\begin{array}{l}\text { Os equipamentos utilizados } \\
\text { em sala e laboratório } \\
\text { encontram-se em perfeito } \\
\text { estado. }\end{array}$ & & $\begin{array}{l}0,84 \\
2\end{array}$ & & & & 0,803 \\
\hline \begin{tabular}{lcll} 
Os & \multicolumn{2}{c}{ ambientes } & oferecidos \\
pela & IES são & limpos & e \\
adequados. & & & \\
adequados.
\end{tabular} & & $\begin{array}{l}0,79 \\
3\end{array}$ & & & & 0,712 \\
\hline $\begin{array}{lll}\text { As instalações } & \text { físicas } & \text { das } \\
\text { salas de } & \text { aula } & \text { são } \\
\text { apropriadas. } & & \\
\end{array}$ & & $\begin{array}{l}0,78 \\
4\end{array}$ & & & & 0,787 \\
\hline $\begin{array}{l}\text { As constantes manutenções } \\
\text { e adequações da estrutura } \\
\text { oferecida pela IES } \\
\text { melhoram o meu bem-estar } \\
\text { como aluno po e } \\
\text { consequentemente a relação } \\
\text { que desenvolvo com a IES. }\end{array}$ & & $\begin{array}{l}0,70 \\
6\end{array}$ & & & & 0,681 \\
\hline $\begin{array}{l}\text { Os professores } \\
\text { exemplos da dam } \\
\text { profítica } \\
\text { à volta. }\end{array}$ & 0,48 & & & & 0,524 & \\
\hline $\begin{array}{l}\text { Os professores fazem } \\
\text { conexão entre a teoria e a } \\
\text { realidade. }\end{array}$ & $\begin{array}{l}0,67 \\
2\end{array}$ & & & & 0,517 & \\
\hline $\begin{array}{l}\text { Há estímulo ao trabalho em } \\
\text { grupo, dentro e fora da sala } \\
\text { de aula. }\end{array}$ & $\begin{array}{l}0,65 \\
4 \\
\end{array}$ & & & 0,57 & & \\
\hline $\begin{array}{l}\text { Há uso de Estudos de Casos } \\
\text { que espelham situações- } \\
\text { problema que colocam o } \\
\text { aluno diante de decisões a } \\
\text { serem tomadas, visando ao } \\
\text { alcance de objetivos. }\end{array}$ & $\begin{array}{l}0,80 \\
3\end{array}$ & & & 0,689 & & \\
\hline $\begin{array}{l}\text { Há uso de variadas técnicas } \\
\text { e estratégias metodológicas } \\
\text { em sala de aula. }\end{array}$ & $\begin{array}{l}0,74 \\
7 \\
\end{array}$ & & & 0,768 & & \\
\hline
\end{tabular}




\begin{tabular}{|c|c|c|c|c|c|c|c|c|c|}
\hline $\begin{array}{l}\text { Há ligação entre uma } \\
\text { disciplina em questão e as } \\
\text { demais disciplinas do curso. }\end{array}$ & & & & 0,59 & & 0,602 & & & \\
\hline $\begin{array}{l}\text { Os professores trazem para a } \\
\text { sala de aula métodos de } \\
\text { ensino diferentes, como } \\
\text { jogos, vídeos ou atividades } \\
\text { que estimulam a prática das } \\
\text { atividades e o processo } \\
\text { ensino-aprendizagem se } \\
\text { torna mais efetivo. }\end{array}$ & & & $\begin{array}{l}0,52 \\
9\end{array}$ & & & 0,718 & & & \\
\hline $\begin{array}{l}\text { Os professores procuram } \\
\text { manter um clima de } \\
\text { liberdade e descontração } \\
\text { com aos alunos, estimulando } \\
\text { sua participação } \\
\text { criatividade. }\end{array}$ & & & $\begin{array}{l}0,63 \\
1\end{array}$ & & & 0,716 & & & \\
\hline Alpha de Cronbach & $\begin{array}{c}0,85 \\
7\end{array}$ & $\begin{array}{c}0,87 \\
1\end{array}$ & $\begin{array}{c}0,85 \\
7 \\
\end{array}$ & $\begin{array}{c}0,86 \\
9 \\
\end{array}$ & $\begin{array}{c}0,60 \\
7\end{array}$ & 0,878 & 0,894 & 0,89 & 0,763 \\
\hline $\mathrm{KMO}$ & & & 0,896 & & & & & & \\
\hline Variância Explicada & & & $67,50 \%$ & & & & & & \\
\hline
\end{tabular}

Fonte: Os autores (2015).

De acordo com a tabela 1, verifica-se que na primeira coleta houve a formação de cinco fatores para um total de 24 itens, todos com carregamentos acima de 0,3 nas dimensões. Os fatores demonstram consistência interna e confiabilidade, pois o Alpha de Cronbach é superior a 0,6. O índice de esfericidade KMO também está adequado com valor de 0,896 e total de variância explicada demonstra um resultado válido totalizando 67,5\%. Com estes resultados pôde-se seguir com a segunda coleta de dados para purificação da escala.

A partir da segunda análise fatorial exploratória, verificou-se que os dados se comportaram de forma distinta a AFE anterior formando quatro dimensões, todas com consistência interna (alpha $>0,6$ ), denominadas de método, professor, estrutura e relacionamento. A configuração dos itens nestes fatores está diretamente relacionada aos achados da revisão literária e da pesquisa qualitativa. $O$ valor de $\operatorname{KMO}$ está adequado $(0,940)$ demonstrando ajuste da esfericidade. Ainda, a variância explicada extraída é de 63,4\% sendo superior ao valor adequado (60\%), o que comprova que as dimensões medem verdadeiramente o constructo em questão.

\subsection{VALIDAÇÃO E PROPOSIÇÃO FINAL DA ESCALA DE QUALIDADE DE ENSINO}

Como etapa subsequente para a validação da escala de Qualidade de ensino, realizouse a Análise Fatorial Confirmatória pelo método de estimação Maximum Likehood. A AFC foi 
conduzida considerando os quatro fatores formados e seus itens. Conforme Anderson e Gerbering (1988), este método é um dos mais indicados para teste e desenvolvimento de teoria. Os resultados demonstraram índices de estimação consideráveis (HAIR; ANDERSON; TATHAM; BLACK, 2005): CMIN/DF 3,132, NFI $=0,823, \mathrm{RFI}=0,801, \mathrm{IFI}=0,872, \mathrm{TLI}=$ 0,856, CFI $=0,871$ e RMSEA =0,087. De acordo com o critério de Hair, Anderson, Tatham e Black. (2005), os índices são aceitáveis, pois CMIN/DF deve ser inferior a 5, e as demais medidas de qualidade de ajuste (NFI, RFI, IFI, TLI e CFI) devem ser superiores a 0,9. Para os autores, também, é adequado que o RMSEA seja inferior a 0,08. Os resultados obtidos estão muito próximos do ideal. A Tabela 3 ilustra índices complementares de avaliação da CFA como os pesos, o valor da AVE e a Confiabilidade Composta. Todos os índices demonstraram valores adequados (Carregamento $>0,3 ; \mathrm{CC}>0,7 ; \mathrm{AVE}>0,5)$.

Tabela 2 Análise Fatorial Confirmatória para Qualidade de Ensino.

\begin{tabular}{|c|c|c|c|c|}
\hline Item & Dimensão & Carreg. & $\mathbf{C C}$ & AVE \\
\hline Há estímulo ao trabalho em grupo, dentro e fora da sala de aula. & \multirow{6}{*}{ Método } & 0,783 & \multirow{6}{*}{0,88} & \multirow{6}{*}{0,55} \\
\hline $\begin{array}{l}\text { Há uso de Estudos de Casos que espelham situações-problema que colocam o } \\
\text { aluno diante de decisões a serem tomadas, visando ao alcance de objetivos. }\end{array}$ & & 0,74 & & \\
\hline Há uso de variadas técnicas e estratégias metodológicas em sala de aula. & & 0,72 & & \\
\hline Há ligação entre uma disciplina em questão e as demais disciplinas do curso. & & 0,811 & & \\
\hline $\begin{array}{l}\text { Os professores trazem para a sala de aula métodos de ensino diferentes, como } \\
\text { jogos, vídeos ou atividades que estimulam a prática das atividades e o processo } \\
\text { ensino-aprendizagem se torna mais efetivo. }\end{array}$ & & 0,705 & & \\
\hline $\begin{array}{l}\text { Os professores procuram manter um clima de liberdade e descontração com aos } \\
\text { alunos, estimulando sua participação e criatividade. }\end{array}$ & & 0,691 & & \\
\hline $\begin{array}{l}\text { A maioria dos meus professores procura criar uma atmosfera agradável na sala } \\
\text { de aula. }\end{array}$ & \multirow{8}{*}{ Professor } & 0,754 & \multirow{8}{*}{0,9} & \multirow{8}{*}{0,53} \\
\hline Os meus professores cumprem os prazos nas atividades estabelecidas. & & 0,807 & & \\
\hline Os meus professores dominam o conteúdo da disciplina que lecionam. & & 0,78 & & \\
\hline $\begin{array}{l}\text { Os meus professores possuem criatividade para usar a tecnologia de ensino que } \\
\text { está à disposição nas salas de aula. }\end{array}$ & & 0,731 & & \\
\hline Os meus professores transmitem suas ideias com clareza e de forma efetiva. & & 0,734 & & \\
\hline $\begin{array}{l}\text { Os meus professores apresentam a teoria e aplicação prática dos assuntos } \\
\text { abordados em sala. }\end{array}$ & & 0,758 & & \\
\hline Os professores usam exemplos da prática profissional ou da realidade à volta. & & 0,602 & & \\
\hline Os professores fazem conexão entre a teoria e a realidade. & & 0,635 & & \\
\hline Os laboratórios ofertados pela IES são adequadamente equipados. & \multirow{5}{*}{ Estrutura } & 0,78 & \multirow{5}{*}{0,89} & \multirow{5}{*}{0,62} \\
\hline $\begin{array}{l}\text { Os equipamentos utilizados em sala e laboratório encontram-se em perfeito } \\
\text { estado. }\end{array}$ & & 0,77 & & \\
\hline Os ambientes oferecidos pela IES são limpos e adequados. & & 0,771 & & \\
\hline As instalações físicas das salas de aula são apropriadas. & & 0,828 & & \\
\hline $\begin{array}{l}\text { As constantes manutenções e adequações da estrutura oferecida pela IES } \\
\text { melhoram o meu bem-estar como aluno e consequentemente a relação que } \\
\text { desenvolvo com a IES. }\end{array}$ & & 0,789 & & \\
\hline $\begin{array}{l}\text { O diálogo que tenho com meus professores facilita o meu processo de } \\
\text { aprendizagem. }\end{array}$ & \multirow[b]{2}{*}{ Relacionamento } & 0,789 & \multirow[b]{2}{*}{0,76} & \multirow[b]{2}{*}{0,5} \\
\hline $\begin{array}{l}\text { Quando há respeito mútuo entre professor e aluno no ambiente de sala de aula } \\
\text { eu tenho a oportunidade de ter maior aprendizado. }\end{array}$ & & 0,534 & & \\
\hline
\end{tabular}


Os meus professores estão acessíveis para responder às minhas solicitações fora dos horários de aula.

0,661

Quando tenho fácil acesso ao meu professor fora de sala de aula me sinto mais próximo dele.

Percebo que meus professores organizam suas aulas de tal forma que encorajam a interação entre os alunos em sala de aula.

0,602

Fonte: Os autores (2015).

Para validação discriminante das dimensões, na tabela 4 apresenta-se os valores das correlações (parte inferior da tabela) e os quadrados das correlações (parte superior da tabela). Como interpretação, deve-se observar se as correlações são inferiores a 0,95 e o quadrado das correlações inferior ao valor da AVE (FRANCISCO-MAFFEZZOLI, et al. 2013).

Tabela 3 Validade discriminante das dimensões.

\begin{tabular}{lrrrr}
\hline & Relacionamento & Estrutura & Professor & \multicolumn{1}{c}{ Método } \\
\hline Relacionamento & & 0,401 & 0,740 & 0,634 \\
\hline Estrutura & 0,633 & & 0,549 & 0,472 \\
\hline Professor & 0,860 & 0,741 & & 0,729 \\
\hline Método & 0,796 & 0,687 & 0,854 & \\
\hline \multicolumn{1}{c}{ Confiabilidade } & $\mathbf{0 , 7 6}$ & $\mathbf{0 , 8 9}$ & $\mathbf{0 , 9 0}$ & $\mathbf{0 , 8 8}$ \\
\hline \multicolumn{1}{r}{$\boldsymbol{E}$} & $\mathbf{0 , 4 0}$ & $\mathbf{0 , 6 2}$ & $\mathbf{0 , 5 3}$ & $\mathbf{0 , 5 5}$ \\
\hline
\end{tabular}

Fonte: Os autores (2015).

Os valores das correlações são todos aceitáveis, porém quando estes valores são elevados ao quadrado e comparados com a AVE, verifica-se que algumas dimensões alcançaram uma discriminação parcial.

A escala proposta mensura a qualidade de ensino a partir de quatro perspectivas: o método de ensino, a qualificação do docente, a estrutura da IES e o relacionamento entre alunos e professores. A primeira das dimensões reflete a importância da aplicação de métodos diferentes e estimulantes que possibilitem o entendimento prático da teoria e a liberdade de participação dos alunos na geração de conhecimentos. A segunda dimensão revela a valorização do docente que transmite suas ideias com clareza e ligações entre a teoria e a realidade vivida pelos alunos. A terceira dimensão concede o entendimento de que não há um ensino de qualidade sem um ambiente adequado e com acesso tecnológico. Por último, a quarta dimensão aponta a necessidade das relações sociais no espaço de aprendizagem para uma educação efetiva.

Realizou-se também a Análise Fatorial Confirmatória pelo método de estimação Maximum Likehood para a escala de Qualidade do Relacionamento com a Marca de acordo com a proposta original de Francisco-Maffezzolli (2013), ou seja, considerando as seis 
dimensões do construto. Os resultados demonstraram índices de estimação aceitáveis (Hair; Anderson; Tatham; Black, 2005): CMIN/DF 2,839, NFI =0,846, RFI $=0,824$, IFI $=0,895$, $\mathrm{TLI}=0,878, \mathrm{CFI}=0,894$ e RMSEA $=0,08$. A Tabela 4 apresenta os índices de avaliação da CFA sendo os carregamentos, o valor da AVE e a Confiabilidade Composta. Todos os índices demonstraram valores adequados (Carregamento $>0,3 ; \mathrm{CC}>0,7$; $\mathrm{AVE}>0,5$ ).

Tabela 4 Análise Fatorial Confirmatória para Qualidade do Relacionamento com Marca.

\begin{tabular}{|c|c|c|c|c|}
\hline Item & Dimensão & Carreg. & $\mathbf{C C}$ & AVE \\
\hline $\begin{array}{l}\text { Pelas vantagens que a minha IES me proporciona sinto-me } \\
\text { dependente a ela. } \\
\text { Pelas vantagens que a minha IES me proporciona ela é importante } \\
\text { para mim. } \\
\text { A minha IES possui características que são únicas. } \\
\text { Não tenho a intenção de trocar a minha IES. }\end{array}$ & Interdependência & $\begin{array}{l}0,828 \\
0,789 \\
0,604\end{array}$ & 0,82 & 0,54 \\
\hline $\begin{array}{l}\text { A minha IES dedica tempo ouvindo as minhas necessidades para } \\
\text { desenvolver o serviço mais adequado pra mim. } \\
\text { A minha IES sempre me dá a liberdade de expressar o que eu quero. } \\
\text { Eu faço sugestões construtivas à minha IES para que ela melhore } \\
\text { seus produtos. } \\
\text { A minha IES me encoraja a fazer parte do processo de construção de } \\
\text { seus serviços. } \\
\text { A minha IES sempre me mantem informado de seus novos } \\
\text { desenvolvimentos de serviços. }\end{array}$ & $\begin{array}{l}\text { Intimidade - Amigos } \\
\text { Atenciosos }\end{array}$ & $\begin{array}{l}0,826 \\
0,797 \\
0,551 \\
0,809\end{array}$ & 0,87 & 0,58 \\
\hline $\begin{array}{l}\text { A minha IES me oferece fontes de apoio para o desenvolvimento de } \\
\text { nosso relacionamento. } \\
\text { A minha IES está presente nos meus momentos mais íntimos. } \\
\text { Tenho um grande conhecimento sobre a minha IES. } \\
\text { Me sinto próximo a minha IES. }\end{array}$ & $\begin{array}{l}\text { Intimidade - Amigos } \\
\text { Verdadeiros }\end{array}$ & $\begin{array}{l}0,809 \\
0,609 \\
0,636 \\
0,815\end{array}$ & 0,81 & 0,52 \\
\hline $\begin{array}{l}\text { A minha IES me faz sentir integrado a o grupo de pessoas que } \\
\text { divido afinidades. }\end{array}$ & & 0,845 & & \\
\hline $\begin{array}{l}\text { Sinto-me conectado a minha IES, pois é valorizada no grupo em que } \\
\text { pertenço. } \\
\text { Sinto-me relacionado com o tipo de pessoa que é aluno da minha } \\
\text { IES. } \\
\text { A minha IES permite que eu tenha reconhecimento social. }\end{array}$ & $\begin{array}{l}\text { Autoconexão - } \\
\text { Reconhecimento }\end{array}$ & $\begin{array}{l}0,814 \\
0,786 \\
0,703\end{array}$ & 0,87 & 0,62 \\
\hline $\begin{array}{l}\text { A minha IES me faz sentir bem, mantendo minha auto-estima } \\
\text { elevada. } \\
\text { A minha IES me faz sentir eu mesmo. } \\
\text { A minha IES é compatível com o meu estilo. }\end{array}$ & Autoconexão - Estima & $\begin{array}{l}0,895 \\
0,833 \\
0,791\end{array}$ & 0,88 & 0,71 \\
\hline $\begin{array}{l}\text { Sentimento com a marca da minha IES: Romântico. } \\
\text { Sentimento com a marca da minha IES: Apaixonado. } \\
\text { Sentimento com a marca da minha IES: Sentimental. } \\
\text { Sentimento com a marca da minha IES: Amoroso. }\end{array}$ & Amor & $\begin{array}{l}0,888 \\
0,903 \\
0,819 \\
0,814 \\
\end{array}$ & 0,92 & 0,73 \\
\hline $\begin{array}{l}\text { Considero a minha IES segura. } \\
\text { Considero a minha IES honesta. } \\
\text { Eu posso contar com a minha IES. } \\
\text { Eu confio na minha IES. }\end{array}$ & Confiança & $\begin{array}{c}0,739 \\
0,852 \\
0,914 \\
0,92\end{array}$ & 0,92 & 0,74 \\
\hline $\begin{array}{l}\text { A minha IES significa muito pra mim. } \\
\text { A minha IES me trata como um cliente especial, e não somente } \\
\text { como mais um cliente. } \\
\text { Eu me sinto parte da IES quando estou usando algum produto da } \\
\text { IES. }\end{array}$ & Comprometimento & $\begin{array}{l}0,865 \\
0,786 \\
0,734\end{array}$ & 0,84 & 0,63 \\
\hline
\end{tabular}

Fonte: Os autores (2015). 
Como análise complementar computou-se a média geral para as dimensões das escalas de qualidade de ensino e da qualidade do relacionamento com a marca. Verificou-se a diferença das médias das dimensões pelo test T-Student para algumas variáveis categóricas: sexo, pagamento da mensalidade e período do curso. A amostra é composta por 125 homens e 160 mulheres, 124 bolsistas e 161 não bolsistas, 179 alunos no início do curso (até o quarto semestre) e 106 alunos no final do curso (do quinto ao oitavo semestre).

Tabela 5 Comparação de grupos para a qualidade de ensino.

\begin{tabular}{lrrrrrrrr}
\hline & \multicolumn{2}{c}{ METODO } & \multicolumn{2}{c}{ PROFESSOR } & \multicolumn{2}{c}{ ESTRUTURA } & \multicolumn{2}{c}{ RELACIONAMENTO } \\
\hline Homem x Mulher & $7,46^{*}$ & $7,81^{*}$ & $7,82^{*}$ & $8,20^{*}$ & 7,73 & 7,92 & $7,97^{*}$ & $8,28^{*}$ \\
\hline Bolsista x Não Bolsista & 7,85 & 7,51 & 8,20 & 7,92 & $8,09^{*}$ & $7,65^{*}$ & 8,26 & 8,06 \\
\hline Inicio x Final do curso & $7,91^{*}$ & $7,23^{*}$ & $8,37^{*}$ & $7,47^{*}$ & $8,34^{*}$ & $6,99^{*}$ & $8,35^{*}$ & $7,79^{*}$ \\
\hline
\end{tabular}

Fonte: Os autores (2015).

Nota-se que há uma diferença significativa para homens e mulheres no que se refere ao método de ensino, professor e relacionamento, sendo a maior média em todos os casos para as mulheres. Verifica-se também que alunos bolsistas tem uma média superior e estatisticamente significativa no que se refere à percepção da qualidade da estrutura. Por último, observa-se que alunos no início do curso percebem como superior todas as dimensões da qualidade de ensino, havendo uma diferença estatisticamente significativa em relação aos que estão no final do curso.

Tabela 6 Comparação de grupos para qualidade do relacionamento com marca.

\begin{tabular}{|c|c|c|c|c|c|c|c|c|c|c|c|c|}
\hline & \multicolumn{2}{|c|}{ INTER } & \multicolumn{2}{|c|}{ INTIM } & \multicolumn{2}{|c|}{$\mathbf{A C}$} & \multicolumn{2}{|c|}{ AMOR } & \multicolumn{2}{|c|}{ CONF } & \multicolumn{2}{|c|}{ COMP } \\
\hline Homem x Mulher & $8,00^{*}$ & $8,35^{*}$ & $7,43^{*}$ & $7,85^{*}$ & 7,51 & 7,85 & $8,06^{*}$ & $8,45^{*}$ & 7,27 & 7,60 & 6,56 & 7,06 \\
\hline Bolsista x Não Bolsista & 8,29 & 8,13 & 7,78 & 7,59 & $7,92 *$ & $7,52^{*}$ & $8,49^{*}$ & $8,12 *$ & 7,63 & 7,32 & $7,16^{*}$ & $6,59 *$ \\
\hline Inicio $x$ Final do curso & $8,47^{*}$ & $7,73^{*}$ & $7,89^{*}$ & $7,29 *$ & $8,16^{*}$ & $6,90^{*}$ & $8,54^{*}$ & $7,84^{*}$ & $7,75^{*}$ & $6,95^{*}$ & $7,26^{*}$ & $6,12 *$ \\
\hline
\end{tabular}

Fonte: Os autores (2015).

No que se refere à qualidade do relacionamento com a marca, as mulheres apresentam médias superiores para todas as dimensões, sendo a diferença estatisticamente significativa para interdependência, intimidade e amor à marca. Os bolsistas têm médias maiores do que os não bolsistas, sendo esta diferença estatisticamente significativa para autoconexão, amor e comprometimento com a marca. Ao fim, verifica-se que para todas as dimensões os iniciantes nos cursos apresentam médias mais altas do que aqueles que estão já no final do curso, havendo diferença estatisticamente significativa em todas as dimensões. 


\subsection{TESTE DA HIPÓTESE}

De acordo com o objetivo do estudo de avaliar o impacto da qualidade de ensino na qualidade do relacionamento com a marca da IES, realizou-se o teste do modelo estrutural. O ajuste geral do modelo foi: $\mathrm{CMIN} / \mathrm{DF} 2,315, \mathrm{NFI}=0,801, \mathrm{RFI}=0,788, \mathrm{IFI}=0,876, \mathrm{TLI}=$ $0,867, \mathrm{CFI}=0,875$ e RMSEA $=0,068$. O poder de explicação da Qualidade de ensino sobre a Qualidade do Relacionamento com a Marca foi registrado em 75,9\%, confirmando a hipótese do estudo.

Como explicação adicional, testou-se no modelo algumas variáveis moderadoras, sendo elas: condição de pagamento (bolsista ou não bolsista), gênero e período em que estuda (curso no início até o $4^{\circ}$ semestre ou curso no final do $5^{\circ}$ ao $8^{\circ}$ semestre). Para todas as moderações encontrou-se resultados significativos, conforme tabela 8.

Tabela 7 Moderação da relação.

\begin{tabular}{|c|c|c|c|c|c|c|c|c|c|c|}
\hline Modelo & $\chi^{2}$ & df & $\Delta \chi^{2}$ & $\Delta \mathbf{d f}$ & Sig & IFI & TLI & CFI & RMSEA & QE->QRM \\
\hline Livre (B/NB) & 3422,1 & 1698 & \multirow{2}{*}{12,025} & \multirow{2}{*}{2} & \multirow{2}{*}{$<0,05$} & 0,821 & 0,808 & 0,819 & 0,06 & $\mathrm{~B}=0,659 * / \mathrm{NB}=0,817 *$ \\
\hline Travado(B/NB) & 3434,125 & 1700 & & & & 0,821 & 0,807 & 0,818 & 0,06 & $\mathrm{~B}=0,718 * / \mathrm{NB}=0,835^{*}$ \\
\hline Livre $(\mathrm{H} / \mathrm{M})$ & 3477,534 & 1698 & \multirow{2}{*}{10,414} & \multirow{2}{*}{2} & \multirow{2}{*}{$<0,05$} & 0,814 & 0,8 & 0,812 & 0,06 & $\mathrm{M}=0,782 * / \mathrm{F}=0,698^{*}$ \\
\hline Travado $(\mathrm{H} / \mathrm{M})$ & 3487,948 & 1700 & & & & 0,813 & 0,799 & 0,811 & 0,06 & $\mathrm{M}=0,801 * / \mathrm{F}=0,749 *$ \\
\hline Livre (CI/CF) & 3422,97 & 1698 & \multirow{2}{*}{12,096} & \multirow{2}{*}{2} & \multirow{2}{*}{$<0,05$} & 0,814 & 0,8 & 0,812 & 0,06 & $\mathrm{CI}=0,78^{*} / \mathrm{CF}=0,696^{*}$ \\
\hline Travado $(\mathrm{CI} / \mathrm{CF})$ & 3435,066 & 1700 & & & & 0,813 & 0,799 & 0,811 & 0,06 & $\mathrm{CI}=0,811 * / \mathrm{CF}=0,72^{*}$ \\
\hline
\end{tabular}

Fonte: Os autores (2015).

Ao comparar o resultado dos grupos comparados, dois a dois, inicialmente, percebe-se que o modelo estrutural proposto é robusto o suficiente para apresentar relações significativas em todos os grupos. De acordo com a análise da significância da diferença do $\chi 2$ para 2 graus de liberdade e intervalo de confiança de 95\%, verifica-se que há diferença significativa na comparação entre todos os grupos $\left(\Delta \chi^{2}>5,991\right)$. De forma geral, pode-se afirmar que a qualidade do ensino tem um impacto maior na qualidade do relacionamento com a marca para alunos que pagam integralmente suas mensalidades, homens e que estão no início do curso.

\section{CONSIDERAÇÕES FINAIS}

O estudo traz duas contribuições importantes, a proposição de uma nova escala para mensuração da qualidade de ensino e a verificação da influência deste construto na qualidade do relacionamento dos alunos com a marca da instituição de ensino superior. Nesse sentido, foi comprovado que, para criar relacionamento entre aluno e marca da IES, deve-se investir na excelência do ensino. 
Ou seja, não há relacionamento sem a entrega adequada do principal serviço oferecido por uma instituição de ensino. Falhas, por exemplo, na entrega do serviço e expectativas não atendidas levam a relacionamentos de baixa intensidade. $\mathrm{E}$, devido ao crescimento do número de instituições de ensino superior (IES) no Brasil (MAINARDES; DOMINGUES, 2010), é cada vez necessário que a gestão universitária se atente com a qualidade dos serviços e com a satisfação de seus alunos (WALTER; TONTINI; DOMINGUES, 2005) em busca de sua sobrevivência em um ambiente cada vez mais competitivo.

Portanto, a gestão do relacionamento entre a instituição de ensino superior e seus alunos realizada por aquela é necessária e premente, visando a satisfação e a retenção dos mesmos (SCAGLIONE; PIZA, 2011) e, consequentemente, uma vantagem competitiva no mercado (ALVES, 2003).

O presente estudo também encontrou que a relação entre a qualidade de ensino e o relacionamento com a marca é moderada pela condição de pagamento (se o aluno é bolsista ou não), gênero e período em que estuda. Neste sentido, há um perfil que se relaciona melhor com a marca à medida que recebe um serviço de qualidade, representado por homens iniciantes no curso oferecido pela instituição que pagam integralmente a mensalidade para a instituição. Depreende-se disso que, de maneira geral, estudantes não bolsistas, talvez pelo fato de necessitarem dispender recursos financeiros para cursarem em uma instituição de ensino, almejam uma qualidade de ensino superior e que tal impacta positivamente no seu relacionamento com a (marca da) instituição de ensino.

Por tudo isso, entende-se que o presente trabalho apresentou uma contribuição teórica ao propor uma nova escala de mensuração e também ao verificar a influência da qualidade de ensino no relacionamento do aluno com a marca da instituição de ensino superior. Nota-se também que há contribuições gerenciais importantes a partir dos resultados encontrados. Para Santini, Guimarães e Severo (2014), entender a intensidade do relacionamento pode contribuir para a assertividade das decisões gerenciais no que tange ao investimento em ações de manutenção de alunos e captação de novos estudantes. Sendo assim, as instituições de ensino devem, se já não o fazem, gerir o relacionamento dos seus alunos não só com a marca em si, mas também com a própria instituição, pois ambas impactam na satisfação e na fidelização dos alunos à instituição. Para tanto, é pujante a busca incessante por qualidade no ensino, já que os estudantes a almejam e tal fato auxilia na manutenção dos mesmos na instituição em um mercado cada vez mais competitivo. 
Como limitação deste estudo tem-se o baixo número de respondentes nas duas coletas de dados quantitativos, o que impactou severamente nos resultados de validação da escala. Os resultados não são passíveis de generalização, pois trata-se de um estudo inicial e restrito a uma IES, assim, outras pesquisas deverão ser replicadas para revelar maior validade externa dos achados. Sugere-se a inclusão de outras variáveis de moderação para possibilitar novas explicações.

\section{REFERÊNCIAS}

Aaker, J. L. Dimensions of brand personality. Journal of marketing research, 347-356, 1997.

ALVES, H. M. B. Uma abordagem de marketing à satisfação do aluno no ensino universitário público: índice, antecedentes e conseqüências. 2003, 286f. Tese (Doutorado em Gestão) Departamento de Gestão e Economia, Universidade da Beira Interior, Covilhã, Portugal, 2003.

ASHWORTH, L.; DACIN, P.; THOMSON, M. Why on earth do consumers have relationships with marketers? Toward understanding the functions of brand relationships. In MACLNNIS, D. J.; PARK, C. W.; PRIESTER, J. R. Handbook of Brand Relationships. New York: M.E. Sharpe, Inc. 2009.

CALDERÓN, Adolfo Ignácio. Universidades mercantis: a institucionalização do mercado universitário em questão. São Paulo em perspectiva, v. 14, n. 1, p. 61-72, 2000.

ALMEIDA, CRS de. O brasão e o logotipo: um estudo das novas universidades na cidade de São Paulo. Rio de Janeiro: Vozes, 2001.

BELK, R. W. Possessions and the extend self. Journal of Consumer Research, 15, 139-168, 1988.

BERGAMO, F. V. M.; GIULIANI, A. C. A lealdade do estudante baseada na qualidade do relacionamento: uma análise em instituições de ensino superior. XXXIII Encontro Nacional da Associação Nacional dos Programas de Pós-Graduação em Administração-ANPAD, 2009.

CHURCHILL JR, G.A. A paradigm for developing better measures of marketing constructs. Journal of marketing research, p. 64-73, 1979.

Costa, A., Costa, R. O.; Bergamo, F. V. m. Marketing de Relacionamento em Instituições Educacionais: uma análise em uma instituição universitária. Revista Formadores, 7(2), 35, 2014.

FOURNIER, S. Consumers and their brands: Developing relationship theory in consumer research. Journal of consumer research, v. 24, n. 4, p. 343-353, 1998. 
FRANCISCO-MAFFEZZOLLI, E. C. et al. A Qualidade do Relacionamento com Marca e as Implicações sobre a Lealdade. RAC-Revista de Administração Contemporânea, v. 17, n. 2, p. 154-175, 2013.

Gummesson, E. Marketing de relacionamento total. 3 ed. Porto Alegre: Bookman, 2010.

HENNIG-THURAU, T.; LANGER, M.; HANSEN, U. Modeling and Managing Student Loyalty: an approach based on the concept of relationship quality. Journal of Service Research, v. 3, n. 4, p. 331-344, May. 2001.

Ikeda, A. A.; Bacellar, F. C. T. Revelando e compreendendo o relacionamento professoraluno em marketing. Revista de Administração Mackenzie. 9 (5), 137-154, 2008.

Karawejczyk, T. C.; Estivalete, V. F. B. O Sentido do Trabalho e o Desenvolvimento de Competências: Perspectivas sob a Ótica do Professor Universitário. Anais do Encontro de Estudos Organizacionais. Recife, Brasil, 2002.

Kotler, P.; Fox, K. F. A. Marketing estratégico para instituições educacionais. São Paulo: Atlas, 1994.

Mainardes, E. W.; Domingues, M. J. C. S. Lealdade de estudantes em instituições de ensino superior: um estudo multicaso em Joinville-SC. eGesta. Revista eletrônica de Gestão de Negócios, v. 6, n. 3, 2010.

Nossa, V. Formação do corpo docente dos cursos de graduação em contabilidade no Brasil: uma análise crítica. Caderno de Estudos FIPECAFI, 21, 1999.

Prado, P.H.M. A avaliação do relacionamento sob a ótica do cliente: um estudo em bancos de varejo. Tese de Doutoramento, São Paulo: Fundação Getúlio Vargas - FGV, 2004.

Prado, P. H. M.; Lima, M. V. V.; Santos, T.; Francisco-Maffezzolli, E. C.; Semprebom, E.; Ribeiro, C. M. A relação de interdependência do consumidor com marca: o desenvolvimento de uma escala de mensuração. Anais do Encontro Nacional da Associação Nacional de Pós-Graduação e Pesquisa em Administração, São Paulo, SP, Brasil, 33, 2009.

Rogers, C. R. Liberdade para aprender. Belo Horizonte: Interlivros, 1972.

Rossiter, J.R. The C-OAR-SE procedure for scale development in marketing. International Journal of Research in Marketing. 19, 305-335, 2002.

Santini, F. O.; Guimarães, J. C. F.; Severo, E. A. Qualidade, comprometimento e confiança na retenção de alunos no ensino superior. Revista Gestão Universitária na América LatinaGUAL 7.1 (2014): 274-297.

Santos, S. C. O processo de ensino-aprendizagem e a relação professor-aluno: aplicação dos "sete princípios para a boa pratica na educação do ensino superior. Caderno de Pesquisas em Administração, 8 (1), 2001. 
Scaglione, V. L. T.; Piza, V. T. Estratégias de marketing aplicadas a instituições de educação superior privadas. Gestão universitária na América Latina, Florianópolis, v.4, n. 2, p. 167$181,2011$.

Tani, G. Avaliação das condições do ensino de graduação em educação física: garantia de uma formação de qualidade. Revista Mackenzie de Educação Física e Esporte. 6 (2), 55 70, 2007.

Thomson, M.; MacInnis, D. J.; Park, C. W. The ties that bind: Measuring the strength of consumers' emotional attachments to brands. Journal of consumer psychology, 15(1), 7791, 2005.

Vieira, P. R. C.; Troccoli, I. R.; Silva, J. M. C. (2011) A Relevância do Corpo Docente na Qualidade Percebida em Serviço de Ensino Superior no Brasil: um Estudo com Modelagem de Equações Estruturais. Revista Economia \& Gestão, 11 (26), 2011.

WALTER, S. A.; TONTINI, G.; DOMINGUES, M. J. C. S. Identificando oportunidades de melhoria em um curso superior através da análise da satisfação dos alunos. In: Encontro Nacional da Associação Nacional dos Programas de Pós-Graduação em AdministraçãoANPAD, 29, 2005, Brasília. Anais... Brasília, XXIX ENANPAD, 2005. 